Special issue of the 3rd International Conference on Computational and Experimental Science and Engineering (ICCESEN 2016)

\title{
The Influence of Tool Tilt Angle on 1050 Aluminum Lap Joint in Friction Stir Welding Process
}

\begin{abstract}
Z. BARLAS*
Sakarya University, Faculty of Technology, Department of Metallurgical and Materials Engineering, Sakarya, Turkey

In this paper, the effect of tool tilt angle on tensile-shear failure load and weld zone properties for 1050 aluminum plates, welded by friction stir lap welding, were investigated. For this purpose, tool tilt angle was varied from $0^{\circ}$ to $5^{\circ}$ under the constant other parameters, such as tool geometry, tool rotation speed of $1200 \mathrm{rpm}$ and tool travel speed of $30 \mathrm{~mm} / \mathrm{min}$. The tensile-shear test was employed to test the mechanical properties of the joint. Optical microscope examinations, microhardness and temperature measurements were also performed in weld zone of lap joints. According to overall results, the tool tilt angle has a reasonable influence on the joint soundness and weld defect formation. If the tool axis was perpendicular to plate surface or a larger tool tilt angle was used, such configurations had harmful effect for the weld zone. In such case the tensile-shear failure load dropped from $4853 \mathrm{~N}$ to $2799 \mathrm{~N}$. Recorded peak temperatures varied from $381^{\circ} \mathrm{C}$ to $438^{\circ} \mathrm{C}$ in the weld center. The measured mean hardness values of the stir and heat-affected zones were $31.5 \mathrm{HV}$ and $28.3 \mathrm{HV}$, respectively, which are lower than that of aluminum 1050 base metal $(40.7 \mathrm{HV})$.
\end{abstract}

DOI: 10.12693/APhysPolA.132.679

PACS/topics: 81.20.Vj, 87.15.La

\section{Introduction}

Aluminum materials are still remaining the research subject in many industrial applications due to their low density, high strength and thermal conductivity features. 1XXX group unalloyed aluminum has been used in architectural trim, heat exchangers, chemical equipment, electric power transmission lines, etc. due to its good corrosion resistance and formability, high conductivity and fairly low strength $[1-3]$.

Due to these properties, aluminium plates can be welded by various methods, and, in particular, by friction stir welding (FSW). Many researchers have studied joining of 1XXX series aluminum and have found that FSW parameters have key roles in obtaining a sufficient joint performance and microstructural evolution [4-10].

Miranov et al. [7] pointed out that the weld strength of Al-1050 decreased with increasing tool rotation speed, since high rotation speed led to softening in the weld zone because of rising temperature. Mosallaee and Dehghan [8] applied different tool rotation speeds and weld speeds to FSW of Al-1100 plates. They have concluded that the increase of the values of these parameters causes at first an improvement of mechanical properties due to grain refinement, and then worsening, due to grain growth. Uygur [9] studied the influence of shoulder diameter in FSW of Al-1050. Author reported that as shoulder diameter was increased, tensile strength and ductility had seriously decreased because of softening in the heat affected zone (HAZ). According to Dawood et al. [10], in cases when the tool rotation speed is sometimes low and sometimes high during the FSW of the pure aluminum,

\footnotetext{
*e-mail: barlas@sakarya.edu.tr
}

the strength of the aluminum weakens because of the excessive or insufficient heat input produced. This article focuses on the investigation of the influence of tool tilt angle on the properties of friction stir lap welded unalloyed Al-1050.

\section{Materials and methods}

Commercially pure 1050 aluminum rolled plate $(150 \times$ $75 \times 3 \mathrm{~mm}^{3}$ ) with chemical composition of $0.113 \mathrm{Si}$, $0.18 \mathrm{Fe}, 0.01 \mathrm{Mg}$, balance $\mathrm{Al}$ (in wt.\%) was chosen as base metal for FSW in lap joint configuration. The welding tool, consisting of a concave shoulder with a diameter of $15 \mathrm{~mm}$ and a frustum shaped and left-handed treated pin with length of $4.8 \mathrm{~mm}$, was utilized to weld joints (Fig. 1a). 1.2379 steel was selected for the tool material. The tool rotation speed and tool travel speed were chosen as $1200 \mathrm{rpm}$ and $30 \mathrm{~mm} / \mathrm{min}$, respectively. Tool penetration depth of $4.9 \mathrm{~mm}$ and clockwise tool rotation direction are the other constant parameters.

Vertical tool loads during the FSW process were simultaneously recorded with a data acquisition system, connected with two load-cells, placed under the backing plate. The tool was tilted by $1.5^{\circ}, 2.5^{\circ}$ and $5^{\circ}$, as well as kept perpendicular to the surface of plates $\left(0^{\circ}\right)$, to examine the effects of the tilt angle on the welding performance.

A K-type thermocouple with $1 \mathrm{~mm}$ diameter was embedded into a hole in order to measure the increment of temperature, close to the lapped interface of plates, as shown in Fig. 1b. The tensile-shear and Vickers microhardness tests were applied to characterize the mechanical features of welds. Tensile-shear specimens with $25 \mathrm{~mm}$ width were tested by a Shimadzu tester with the crosshead speed of $2.5 \mathrm{~mm} / \mathrm{min}$. The hardness testing was carried out on the metallographic examination sample, at $100 \mathrm{~g}$ load and $10 \mathrm{~s}$ dwell time. Cross-sectional 
areas of specimens were etched by Keller reagent and then a Nikon Eclipse L150A optical microscope was utilized for the metallographic inspection.
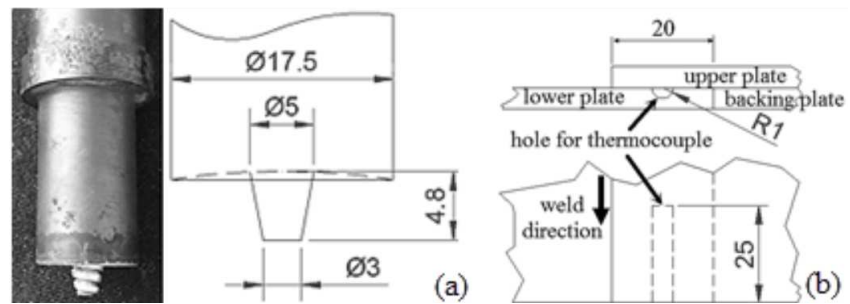

Fig. 1. (a) Tool image and its geometry, (b) schematic representation of the hole for thermocouple placement.

\section{Results and discussion}

The weld surfaces are given in Fig. 2. The visual inspection shows that defect-free Al-1050 welds were successfully made in the lap joint configuration by FSW. The surface quality of the joints is very good; this means that the used constant parameters are suitable for the process. On the other hand, the weld flash was clearly observed at tool tilt angle of $5^{\circ}$. Few flashes have also occurred at $0^{\circ}$ due to the leading edge of the tool shoulder. Therefore, it can be said that if the tool was not tilted or was extremely tilted by a large angle, it caused more weld flash formation.

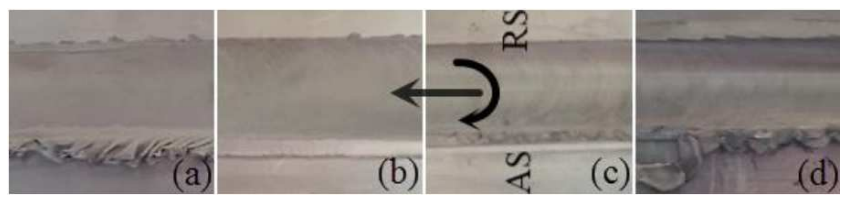

Fig. 2. Weld surface appearance of the friction stir welded Al-1050 at (a) $0^{\circ}$, (b) $1.5^{\circ}$, (c) $2.5^{\circ}$ and (d) $5^{\circ}$.

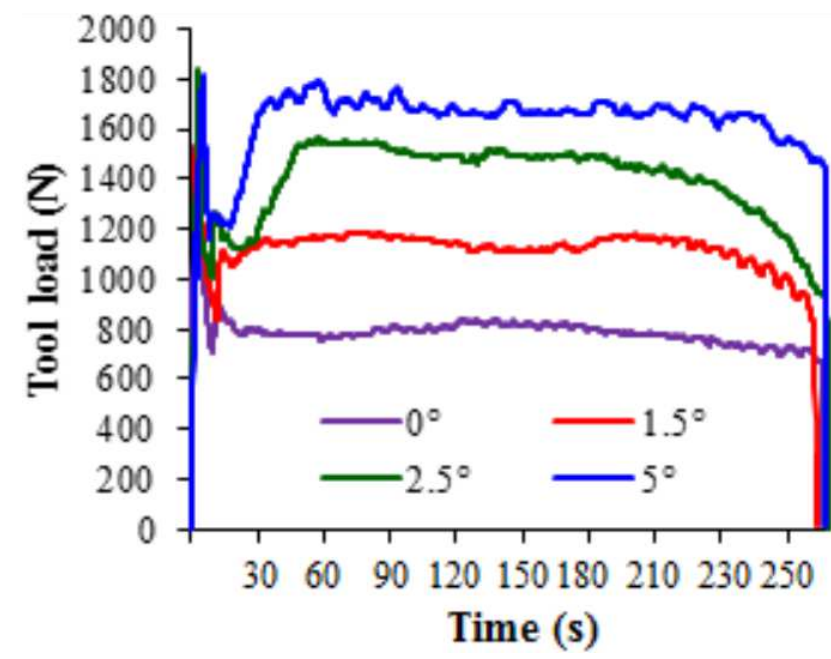

Fig. 3. Vertical tool load distributions, depending on the tool tilt angle.
The plot in Fig. 3 shows the vertical tool loads on the work-pieces during the FSW. The vertical load increased with the increasing tool tilt angle. That is to say, the forging force, which is important to squeeze the plasticized and extruded material, was influenced by the tool tilt angle. It is noticed that volumetric defects such as wormhole, tunnel-like and cavity defects have been formed depending on level of forging force. Hence, an intense mixing and transporting of defect-free material might be expected at higher tilt angles.

According to the temperature measurements, the tool tilt angle has a distinctive effect on the rising temperature. The values increased with increasing the level of tilt angle. The peak temperatures of welds at $0^{\circ}$ and $5^{\circ}$ were measured as $381^{\circ} \mathrm{C}$ and $438^{\circ} \mathrm{C}$, respectively. These values are high enough to induce recrystallization for 1050 aluminum.

Consequently, the tool tilt angle has a significant role in rising the forging force, heat generation and peak temperature.

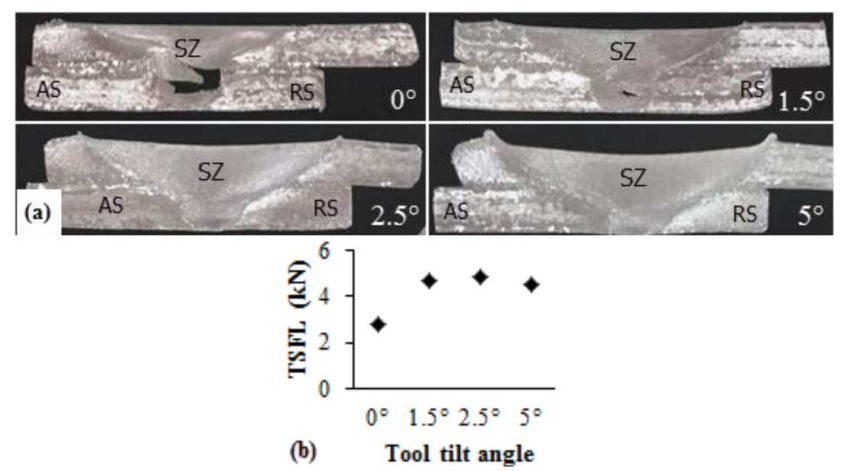

Fig. 4. (a) Macro-images of transverse cross-section and (b) tensile-shear failure loads of the welds made at different tool tilt angles.

Figure 4a shows the cross-sectional weld zone obtained at different tool tilt angles. Weld zone formation, material transportation and defect occurrence were significantly influenced by the tool tilt angle. A tunnel-like defect was obviously seen in the stir zone (SZ) for the weld at $0^{\circ}$. This means that plasticized material was not sufficiently transported from the leading edge of the pin to the cavity because of low heat generation and vertical forces. Similar observation was reported by Barlas and Ozsarac [11], who studied the effect of tool tilt angle for 5754 aluminum alloy.

The defect size was reduced at tool tilt angle of $1.5^{\circ}$ due to increment in the downward force. Furthermore, there is no evidence of such defects at $2.5^{\circ}$ and $5^{\circ}$. As suggested by Kumar and Kailas [12], insufficient vertical tool load and frictional heat generation, which depend on the tool tilt angle level, cause defects inside of the weld. On the other hand, the weld flash had formed at $5^{\circ}$, as was mentioned earlier. The weld flash formation resulted in reducing the upper plate thickness of this joint. 
Considering the tool axis, symmetrical and bottle nipple-shaped SZs were produced in all welds. However, the nipple region had widened with increasing the tilt angle toward both, the advancing side (AS) and the retreating side (RS). In addition, SZ region has gradually grown with the increasing tilt angle. These observations imply that the tool tilt angle affects the amount of stirred material.

Average tensile-shear failure loads (TSFL) of the welds are presented in Fig. 4b. The lowest TSFL was determined at $0^{\circ}$ as $2799 \mathrm{~N}$, in accordance with above macroscopic assessments. The other welds have shown close values, in spite of the presence of a small cavity defect at $1.5^{\circ}$ and the thinned upper plate at $5^{\circ}$. It is believed that these defects do not have a significant influence on TSFL, since the cross-sectional area of SZ in the lap joint configuration was larger than the other sections in the weld zone. The highest obtained TSFL was $4853 \mathrm{~N}$, at the tool tilt angle of $2.5^{\circ}$.

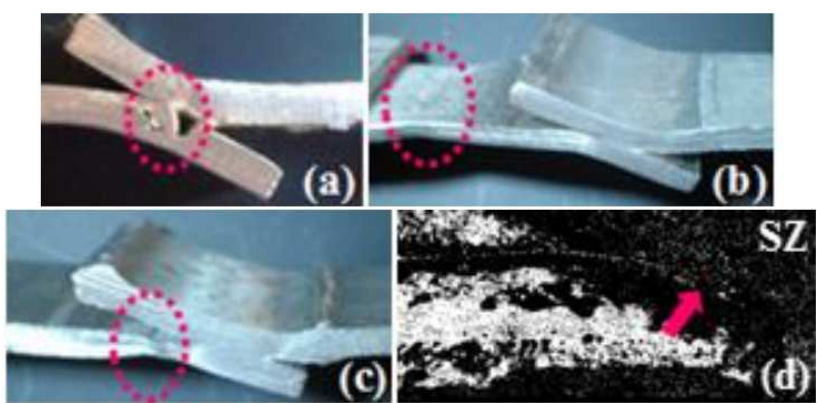

Fig. 5. Failure locations on the welded specimens at (a) $0^{\circ}$, (b) $2.5^{\circ}$, (c) $5^{\circ}$ and (d) un-bonded interface between plates at $5^{\circ}$.

The dashed ellipses in Fig. $5 \mathrm{a}-\mathrm{c}$ show the failure location on the tested specimens. The samples of welds at $1.5^{\circ}$ and $2.5^{\circ}$ failed in similar location and this indicates that the used parameters were enough to obtain a sound lap joint. On the other hand, when a relatively high level of tool tilt angle $\left(5^{\circ}\right)$ was applied, the un-bonded overlapped interface was forced toward the nipple region (indicated by the arrow in Fig. 5d). In this case, the length between the tip of un-bonded interface and bottom of the lower plate is less than the length of other section, which explains why TSFL of the weld at $5^{\circ}$ was relatively lower.

Figure 6 depicts the microstructures as well as the microhardness profile along the mid-section, at the upper plate, for the joint at $2.5^{\circ}$, which has the highest TSFL. The weld zone consists of SZ with the recrystallized fine grains and HAZ with coarse grains, as well as the base metal (BM). However, a distinctive thermo-mechanically affected zone, which is characterized by the elongated grains between HAZ and SZ, was not detected in the weld zone.

According to the microhardness measurements, SZ and HAZ have softened due to the thermal annealing effect. The average hardness of SZ, HAZ and BM is $31.5 \mathrm{HV}_{0.1}$, $28.3 \mathrm{HV}_{0.1}$ and $40.7 \mathrm{HV}_{0.1}$, respectively. The heat input by FSW process has caused the decrease in hardness of the work-hardening aluminum due to the recovery and recrystallization. Nevertheless, the hardness of SZ is higher than that of HAZ. This can be attributed to the grain size refinement in SZ.
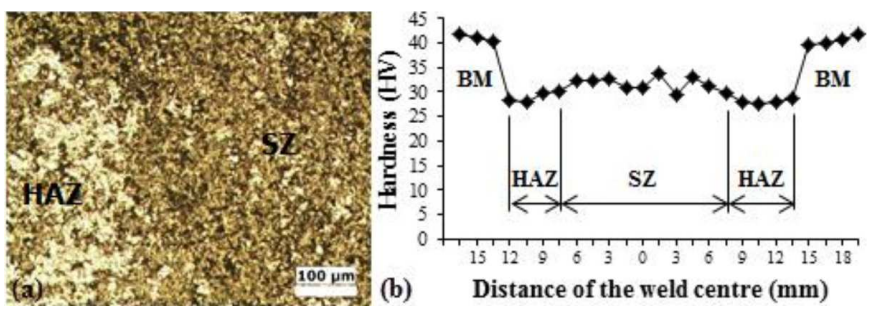

Fig. 6. (a) Micro-image and (b) microhardness distribution in the weld zone of the joint at $2.5^{\circ}$.

\section{Conclusions}

The lapped Al-1050 plates were joined by FSW under various tool tilt angles of $0^{\circ}-5^{\circ}$, while the other parameters were kept constant. The main conclusions resulting from the experimental studies are summarized as follows: 1) The weld zone and tensile-shear properties of joints were influenced by the tool tilt angle. 2) When the tool was adjusted perpendicular to the plate surface, a large tunnel-like defect and a decrease in the failure load were observed. 3) The vertical tool load has increased with increasing tool tilt angle. 4) The best joint performance of about $4.8 \mathrm{kN}$ was achieved at $2.5^{\circ}$. 5) The peak temperatures changed from $381^{\circ} \mathrm{C}$ to $438^{\circ} \mathrm{C}$. 6) The weld zone consisted of SZ and HAZ as well as the base metal. 7) The average hardness of SZ and HAZ was lower than that of BM.

\section{References}

[1] M. Koru, O. Serce, Acta Phys. Pol. A 130, 453 (2016).

[2] A. Akkas, A.B. Tugrul, B. Buyuk, A.O. Addemir, M. Marsoglu, B. Agacan, Acta Phys. Pol. A 128, B-176 (2015).

[3] A.M. Russell, K.L. Lee, Structure-Property Relations in Nonferrous Metals, Wiley\&Sons, New Jersey 2005.

[4] N. Saito, I. Shigematsu, T. Komaya, T. Tamaki, G. Yamauchi, M. Nakamura, J. Mater. Sci. Lett. 20, 1913 (2001).

[5] M. Lipińska, L. Olejnik, A. Pietras, A. Rosochowski, P. Bazarnik, J. Goliński, T. Brynk, M. Lewandowska, Mater. Design 88, 22 (2015).

[6] M. Boz, A. Kurt, Mater. Design 25, 343 (2004).

[7] S. Mironov, K. Inagaki, Y.S. Sato, H. Kokawa, Metall. Mater. Trans. A 46A, 783 (2015).

[8] M. Mosallaee, M. Dehghan, J. Mater. Engin. Perform. 23, 3786 (2014).

[9] I. Uygur, Arch. Metall. Mater. 57, 53 (2012).

[10] H.I. Dawood, K.S. Mohammed, Z.A. Wahab, Adv. Mater. Res. 795, 182 (2013).

[11] Z. Barlas, U. Ozsarac, Welding J. 91, 16 (2012).

[12] K. Kumar, S.V. Kailas, Mater. Sci. Engin. A 485, 367 (2008). 